\title{
DIFFERENTIATION OF THYROID MALIGNANCIES - AN ULTRASONOGRAPHIC CRITERIA
}

\author{
Vijai Pratap ${ }^{1}$, S.K. Jain²
}

\section{HOW TO CITE THIS ARTICLE:}

Vijai Pratap, SK Jain. "Differentiation of thyroid malignancies- an ultrasonographic criteria". Journal of Evolution of Medical and Dental Sciences 2013; Vol. 2, Issue 44, November 04; Page: 8475-8482.

\begin{abstract}
Numerous studies on Ultrasonographic (US) findings of Thyroid malignancy have been conducted (1-6). The main pathologic types of thyroid carcinoma are papillary, follicular, medullary, and anaplastic. Papillary and follicular thyroid carcinomas both have an excellent prognosis, with a 20 -year survival of $90 \%-95 \%$ and $75 \%$, respectively (7-9). Medullary thyroid carcinoma is more aggressive, with a 10-year survival of 42\%-90\% (10-11). Anaplastic thyroid carcinoma has an extremely poor prognosis, with a 5-year survival of 5\% (10-11). Risk factors for thyroid carcinoma include age of less than 20 years or more than 60 years, a history of neck irradiation, and a family history of thyroid cancer (11.).Thyroid lymphoma, usually of the non-Hodgkin type, is uncommon. It may occur as part of generalized lymphoma or as a primary tumor, usually in the setting of Hashimoto thyroiditis. Metastases to the thyroid are rare and usually originate from primary lung, breast, and renal cell carcinomas. Metastatic disease should be suspected when a solid thyroid nodule is found in a patient with a known non-thyroid malignancy. AIMS \& OBJECTIVE: In this study we planned to differentiate different type of thyroid malignancies based on Ultrasonography from one another due their different prognosis. MATERIAL \& METHOD: We took 120 patients showing palpable neck masses out of which 40 patients were found to have malignant neoplasm of Thyroid gland. Further differentiation of different type of Thyroid neoplasm was done by Ultrasonography. RESULT: Out of 40 malignant neoplasm, 24 patients had papillary carcinoma and 4 patients had medullary carcinoma Thyroid. Rest 16 patients were kept in other type of thyroid malignancies. CONCLUSION: We concluded our study with the fact that just keeping the patient under category of thyroid neoplasm is just not sufficient, rather we should be able to differentiate each type of thyroid malignancy from one another due to different prognosis of each type.
\end{abstract}

KEYWORDS: ULTRASONOGRAPHY, PAPILLARY CARCINOMA, MEDULLARY CARCINOMA.

INTRODUCTION: Neck masses form a wide and varied pathologic spectrum, ranging from benign inflammatory conditions to frankly ominous malignant lesions. The neck mass may be the presenting complaint or an incidental finding on the general physical examination. Clinical examination alone does not reliably indicate the true nature and extent of a neck lesion.' Imaging plays an essential role in the management of neck disease. (12). Radiological imaging has become a mainstay in the diagnoses and in planning of the management of neck lesions. Conventional radiological techniques have been largely replaced by modern imaging modalities. Ultrasonography (US) and computed tomography (CT) enable radiological characterization of normal and diseased structures in the neck in ways that were previously not possible. With the advent of high frequency ultrasound (US) probes, superficial structures are visualized very conveniently and with great spatial solution. The probes are easy to handle and patient acceptability is very high. (13) predicted an important role of sonography in visualization of benign and malignant tumors of the neck.US is often the first modality used in diagnostic work up of a thyroid nodule. (14). (15) stated the 
importance of imaging with US in defining the morphology, size, extension and infiltration of adjacent structure in staging of thyroid masses.

Features suggestive of normal Thyroid: Normal Thyroid is homogeneous and more echogenic than surrounding muscles.

Sonographic features suggestive of benign and malignant nodules were listed by various authors. (16-19).

\section{Features suggestive of benign nature}

Anechoic: Totally anechoic $20-25 \%$ of all lesions.

Hyperechoic: $15-20 \%$ of thyroid nodules

Hypoechoic: with distal enhancement and possible lateral acoustic shadows.

Calcifications: egg shell type surrounding whole nodule.

\section{Features suggestive of malignant nature}

Hypoechoic without distal enhancement (85-95\% of all neoplasms).

Incomplete, irregularly thickened $(<2 \mathrm{~mm})$ peripheral halo.

Irregular or poorly defined margin.

Microcalcifications (hyperechoc dots of $<2 \mathrm{~mm}$ diameter with or without posterior shadowing).

Invasion of anatomical structures around the thyroid.

Presence of cervical metastatic nodes

MATERIALS \& METHODS: Subjects made available in this study is the result of profound interaction of the faculty of various clinical \& Pre-clinical departments, who used to discuss the patients in regular CME'S held almost every week in TMMC \& RC, TMU, Moradabad, and continuous discussion on every forum for planning and management of patients welfare in terms of investigations (radiological, pathological, and biochemical) and surgical (whether conservative or operational). As a whole we took consideration of 120 patients showing palpable neck masses out of which 40 patients were found to have malignant neoplasm of Thyroid gland. Further differentiation of different type of Thyroid neoplasm was done by Ultrasonography using Scanners with 7-10 MHz transducers on MEDISON Diagnostic ultrasound system installed in Department of Radiodiagnosis TMMC\&RC, TMU, Moradabad.

Institutional Ethical and research committee approval was taken prior to start the study.

Female subjects were examined in presence of female nursing staff and one female attendant.

In case of minor consent from guardians was taken.

Every patient examined in this study gave his/her consent. (Scanned copy of consent form attached (Annexure-1). 
RESULT:

\begin{tabular}{|c|c|c|}
\hline Imaging Features & No. of cases & Percentage \\
\hline \multicolumn{3}{|l|}{ CONSISTENCY } \\
\hline Solid & 20 & $50 \%$ \\
\hline Mixed & 10 & $25 \%$ \\
\hline Predominantly Cystic & 10 & $25 \%$ \\
\hline \multicolumn{3}{|l|}{ ECHOGENECITY } \\
\hline Isoechoic & - & - \\
\hline Hypoechoic & 20 & $50 \%$ \\
\hline Heteroechoic & 20 & $50 \%$ \\
\hline Anechoic & - & - \\
\hline \multicolumn{3}{|l|}{ HALO } \\
\hline Complete, thin well defined & - & - \\
\hline Incomplete, thick ill-defined & 20 & $50 \%$ \\
\hline Absent. & 20 & $50 \%$ \\
\hline \multicolumn{3}{|l|}{ CALCIFICATION } \\
\hline Coarse & 20 & $50 \%$ \\
\hline Micro calcification & 10 & $25 \%$ \\
\hline Rim calcification & - & - \\
\hline Absent & 10 & $25 \%$ \\
\hline \multicolumn{3}{|l|}{ ATTENUATION } \\
\hline Hypodense & 40 & $100 \%$ \\
\hline Isodense & - & - \\
\hline Hyperdense & - & - \\
\hline \multicolumn{3}{|l|}{ ENHANCEMENT } \\
\hline Homogeneous & 10 & $25 \%$ \\
\hline Heterogeneous & 30 & $75 \%$ \\
\hline RIM ENHANCEMENT & 10 & $25 \%$ \\
\hline EXTRATHYROIDAL EXTENSION & 20 & $75 \%$ \\
\hline LYMPHADENOPATHY & 10 & $25 \%$ \\
\hline MULTINODULARITY & 20 & $50 \%$ \\
\hline \multicolumn{3}{|l|}{ MARGINS } \\
\hline Well defined & 10 & $25 \%$ \\
\hline Ill defined & 30 & $75 \%$ \\
\hline
\end{tabular}




\begin{tabular}{|c|c|c|c|}
\hline S.N. & ULTRASONOGRAPHIC FINDINGS & $\begin{array}{l}\text { PAPILLARY CARCINOMA } \\
\qquad \mathrm{N}=24\end{array}$ & $\begin{array}{l}\text { MEDULLARY CARCINOMA } \\
\mathrm{N}=\mathbf{4}\end{array}$ \\
\hline \multirow{5}{*}{1.} & \multicolumn{3}{|l|}{ INTERNAL CONTENT } \\
\hline & a. Solid & 20 & 3 \\
\hline & b. predominantly solid & 4 & 1 \\
\hline & c. predominantly cystic & 0 & 0 \\
\hline & d. $\quad$ cystic & 0 & 0 \\
\hline \multirow{4}{*}{2.} & \multicolumn{3}{|l|}{ SHAPE } \\
\hline & a. ovoid to round & 6 & 2 \\
\hline & b. taller than wide & 8 & 1 \\
\hline & c. irregular & 10 & 1 \\
\hline \multirow{4}{*}{3.} & \multicolumn{3}{|l|}{ MARGIN } \\
\hline & a. smooth & 6 & 1 \\
\hline & b. spiculated & 10 & 2 \\
\hline & c. ill defined & 8 & 1 \\
\hline \multirow{5}{*}{4.} & \multicolumn{3}{|l|}{ ECHOGENICITY } \\
\hline & a. markedly hypoechoic & 13 & 2 \\
\hline & b. hypoechoic & 6 & 1 \\
\hline & c. isoechoic & 3 & 1 \\
\hline & d. hyperechoic & 2 & 0 \\
\hline \multirow{5}{*}{5.} & \multicolumn{3}{|l|}{ CALCIFICATIONS } \\
\hline & a. no calcifications & 5 & 2 \\
\hline & b. microcalcifications & 12 & 1 \\
\hline & c. macrocalcifications & 5 & 1 \\
\hline & d. rim calcifications & 2 & 0 \\
\hline
\end{tabular}

Ultrasonographic differentiation of different thyroid neoplasm was found as under Ultrasound features of papillary carcinoma include:

predominantly solid and hypoechoic presence of punctate microcalcification correspond to psammomas bodies on microscopy ill-defined margins chaotic intranodular vascularity on colour flow imaging adjacent characteristic lymph nodes: cystic necrosis in, microcalcification in , located in the pre/paratracheal regions and along the cervical chains.

Ultrasound features of anaplastic carcinoma include:

hypoechoic tumour diffusely involving the entire lobe or gland ill-defined margin 
areas of necrosis in nodal or distant metastases in $80 \%$ of patients; the involved lymph nodes show evidence of necrosis .

multiple small intranodular vessels on colour flow imaging

extracapsular spread and vascular invasion in a third of patients

\section{Ultrasound features of medullary carcinoma include}

solid hypoechoic nodule

echogenic foci in tumours due to amyloid deposition and associated calcification ; similar deposits are also seen in associated nodal metastases

chaotic intranodular vessels within the tumour on colour flow imaging.

\section{Ultrasound features of follicular lesions include}

hyperechoic/isoechoic in echotexture; hypoechoic lesions have a higher risk of beingmalignant predominantly solid and homogen eous

well-defined, haloed .

benign lesions have a type II vascularity, whereas malignant lesions have a type III vascularity

\section{Ultrasound features of lymphoma of thyroid gland include:}

focal thyroid involvement may be seen as a well-defined nodule with pseudocystic appearance or heterogeneous appearance

diffuse involvement may result in heterogeneous echopattern or simple enlargement of the gland with normal echopattern associated round, hypoechoic, reticulated lymphomatous nodes in the neck background of previous Hashimoto's thyroiditis in the form of echogenic fibrous strands within the thyroid gland is often seen

\section{Ultrasound features of thyroid metastases include}

homogeneous, hypoechoic mass

well-defined margins

predominantly in the lower pole

heterogeneous echopattern when the gland is diffusely involved

multiple, hypoechoic solid, thyroid nodules

chaotic intranodular vascularity.

DISCUSSION: About $20 \%$ of solitary Thyroid nodules are malignant (20). The incidence of various malignancies are:

$\begin{array}{lc}\text { Papillary carcinoma } & 60-80 \% \\ \text { Follicular carcinoma } & 15-18 \% \\ \text { Anaplastic carcinoma } & 3-10 \% \\ \text { Medullary carcinoma } & 4-5 \% \\ \text { Lymphoma } & 5 \%\end{array}$

Hypo echogenicity and an ill-defined margin are known sonographic findings associated with thyroid cancer (21-22). Irregular margins, which result from microinvasion of the surrounding tissues, may also indicate thyroid malignancy (23).Both thick peripheral hypoechoic rim patterns 
and the absence of a rim surrounding a thyroid nodule, which represents pericapsular inflammatory infiltration, have been reported to be in dicators of malignancy (24).

Papillary carcinoma: The commonest thyroid malignancy is papillary carcinoma. It has a peak incidence in the $3^{\text {rd }}$ and $4^{\text {th }}$ decades and is more common in females. The prognosis is the best with this tumor ( $>90 \%$ after 20 years) (25). The peak incidence is in the $5^{\text {th }}$ decade( 26). Common sonographic features of papillary carcinoma included hypoechoic texture (86\%), microcalcifications $(42 \%)$ or no calcifications (47\%), well-defined margins $(47 \%)$, and intrinsic hypervascularity (69\%).Papillary carcinoma imaging features can vary from a well defined slow growing adenoma like form to irregular, heterogeneous mass with necrosis. Thus, it may be important to characterize the ultrasonographic features of PTC patients with Graves' disease. (27). Psammoma body microcalcifications are specific to papillary thyroid cancer (10-11). Sonographic criteria for a thyroid malignancy have been established for a papillary thyroid carcinoma (PTC) in most studies .

Medullary carcinoma: Medullary thyroid carcinoma (MTC) accounts for $3.5-10 \%$ of all thyroid malignancies and lesions are derived from the parafollicular C-cells that produce calcitonin (28). Imaging features are solid nodule, calcification may be seen, local and lymph node extension may also be seen. Medullary thyroid carcinoma (MTC) belongs to the neuroendocrine tumor group (2931).

Follicular carcinoma: The peak incidence is in the $5^{\text {th }}$ decade. ${ }^{78}$ Imaging features can vary from a well defined slow growing adenoma like form to irregular, heterogeneous mass with necrosis and calcifications. Lymph nodes metastasis and occult forms and cystic changes are rare. Thyroid echogenicity reflects the gland's follicular structure. (27))

Anaplastic carcinoma: Anaplastic carcinoma common in the $6^{\text {th }}$ decade, is the most aggressive from with large size and extensive necrosis and hemorrhage (32). Extra thyroid spread is common. These can arise from papillary to follicular carcinomas.

Lymphoma: Thyroid lymphomas may be primary or part of systemic lymphoma. $80 \%$ arise in Hashimoto Thyroiditis. (33).

CONCLUSION: Ultrasound is the most sensitive method for diagnosing thyroid lesions, and is valuable for identifying many malignant and potentially malignant thyroid lesions. Ultrasound features that are helpful in differentiating includes microcalcifications, irregular or microlobulated margins, marked hypoechogenecity, a lesion that is taller than wide, and intranodular vascularity within a solid thyroid nodule.

Radiologists must be familiar with the various signs on ultrasound that help to distinguish benign from malignant thyroid nodules and the typical appearance of common thyroid cancer. In addition, ultrasound provides a safe tool for disease surveillance in patients with thyroid cancer after treatment.

Despite clear identification, no single Ultrasound criterion is reliable in differentiating different malignant thyroid lesions, but many combined US features may aid in predicting the malignant nature of a given nodule. However, the predictive value of these combinations increases at the expense of their sensitivity. 
ACKNOWLEDGEMENT: Authors wish to acknowledge Prof. Pankaj Mishra, Statistician, department of Community medicine (SGRRIMHS, Dehradun) for helping in statistical difficulties which were faced during the course of the study.

\section{REFERENCES:}

1. Moon WJ, Jung SL, Lee JH, Na DG, Baek JH, Lee YH, et al. Benign and malignant thyroid nodules: US differentiation-multicenter retrospective study. Radiology. 2008;247:762-777.

2. Frates MC, Benson CB, Charboneau JW, Cibas ES, Clark OH, Coleman BG, et al. Management of thyroid nodules detected at US: Society of Radiologists in Ultrasound consensus conference statement. Radiology. 2005;237:794-800.

3. Iannuccilli JD, Cronan JJ, Monchik JM. Risk for malignancy of thyroid nodules as assessed by sonographic criteria: the need for biopsy. J Ultrasound Med. 2004;23:1455-1464.

4. Kim EK, Park CS, Chung WY, Oh KK, Kim DI, Lee JT, et al. New sonographic criteria for recommending fine-needle aspiration biopsy of nonpalpable solid nodules of the thyroid. AJR Am J Roentgenol. 2002;178:687-691.

5. Shimura H, Haraguchi K, Hiejima Y, Fukunari N, Fujimoto Y, Katagiri M, et al. Distinct diagnostic criteria for ultrasonographic examination of papillary thyroid carcinoma: a multicenter study. Thyroid. 2005;15:251-258.

6. Chan BK, Desser TS, McDougall IR, Weigel RJ, Jeffrey RB., Jr Common and uncommon sonographic features of papillary thyroid carcinoma. J Ultrasound Med. 2003;22:1083-1090.

7. MiddletonWD, Kurtz AB, Hertzberg BS. Ultrasound: the requisites. 2nd ed. St Louis, Mo: Mosby, 2004; 244-252

8. HarnsbergerH. Diagnostic imaging: head and neck. Salt Lake City, Utah: Amirsys, 2004; 24-43.

9. DahnertW. Radiology review manual. 5th ed. Philadelphia, Pa: Lippincott Williams \& Wilkins, 2003; 394-396.

10. Koike E, Noguchi S, Yamashita H, et al. Ultrasonographic characteristics of thyroid nodules: prediction of malignancy. Arch Surg. 2001;136:334-337.

11. Takashima S, Fukuda H, Nomura N, Kishimoto H, Kim T, Kobayashi T. Thyroid nodules: reevaluation with ultrasound. J Clin Ultrasound. 1995;23:179-184.

12. Sigal R Imaging of cervical masses. J Radiol Dec 1999;30 (12): 1807-15.

13. Howry DH, Stott DA Bliss WR. The ultrasonic visualization of carcinoma of the breast and other soft tissue structures. Cancer 1954 March;351-358.

14. Gooding GA, Sonography of thyroid and parathyroid, Radiol Clin North Am, 1993;31:967-989.

15. Wanebo JE, Malik JM, Vanden Berg SR, et al. Malignant peripheral nerve sneath tumoras. A clinicopathologic study of 28 cases. Cancer 1993; 71: 1247-1253.

16. Krubsack AJ Wilson SD, Lawson TL et al. Prospective comparison of radionuclide, CT, Sonographic and MR localization of parathyroid tumors. Department of Radiology, Medical College of Wisconsin, Milmankee 53226.

17. Moreau JF, Belin X, Rotkopf L, et al. imaging of parathyroid gland Ann Endocrinol (Paris) 1994;55 (5):159-164.

18. Hajek PC, Salomonowitz E, Turk R, et al. Lymph nodes of the neck: evaluation with US. Radiology 1986;153:739. 
19. Pierre Vassalo, Karl Wernecke, Nikolaus et al. Differentiation of benign from malignant superficial lymphadenopathy : The role of high resolution US Radiology 1992;183:215-220.

20. Brown CL. Pathology of the cold nodule. Clinics in endocrinology and metabolism 1981;10:235-245.

21. Noma S, Nishimura K, Togashi K, et al. Thyroid gland: MR imaging. Radiology. 1987;164:495499.

22. Solbiati L, Volterrani L, Rizzatto G, et al. The thyroid gland with low uptake lesions: evaluation by ultrasound. Radiology. 1985;155:187-191

23. Koike E, Noguchi S, Yamashita H, et al. Ultrasonographic characteristics of thyroid nodules: prediction of malignancy. Arch Surg. 2001;136:334-337.

24. Tessler FN, Tublin ME. Thyroid sonography: current applications and future directions. AJR Am J Roentgenol. 1999;173:437-443.

25. Som PM, Scherl MP, Rao VM et al. Rare presentations of ordinary lipomas of the head and neck - a review, Am J Neuroradiol Jul-Aug 1936;7(4):657-664.

26. Enzinger FM, Weiss SW, Soft tissue tumors. ST Louis, Mosby, 1995

27. Marino M, Chiovato L, Pinchera A. Graves' disease. In: DeGroot LJ, Jameson JL, editors. Endocrinology. 5th ed. Philadelphia: W.B. Saunders; 2005. pp. 1995-2028.

28. Melvin KE, Tashjian AH., Jr The syndrome of excessive thyrocalcitonin produced by medullary carcinoma of the thyroid. Proc Natl Acad Sci USA. 1968;59:1216-1222.

29. Lairmore TC, Wells SA Jr. Medullary carcinoma of the thyroid: current diagnosis and management. Semin Surg Oncol 1991; 7:92 -99

30. Kebebew E, Ituarte PH, Siperstein AE, Duh QY, Clark OH. Medullary thyroid carcinoma: clinical characteristics, treatment, prognostic factors, and a comparison of staging systems. Cancer 2000; 88:1139-1148

31. Leboulleux S, Baudin E, Travagli JP, Schlumberger M. Medullary thyroid carcinoma. Clin Endocrinol (Oxf) 2004; 61:299-310

32. Kransdrof MJ, Murphey MD : Imaging of soft tissue tumors. Philadelphia, WB Saunders 1997.

33. Yousem DM, Frank JL, Bilanivk LT, et al. Rhabdomyosarcomas in Head and neck : MR imaging evaluation. Radiology 1990;177:683-686.

\section{AUTHORS:}

1. Vijai Pratap

2. S.K. Jain

\section{PARTICULARS OF CONTRIBUTORS:}

1. Associate Professor, Department of Radiodiagnosis, TMMC \& RC, Moradabad.

2. Professor, Department of Anatomy, TMMC \& RC, Moradabad.
NAME ADDRESS EMAIL ID OF THE CORRESPONDING AUTHOR:

Dr. S.K. Jain,

Professor, Department of Anatomy, TMMC \& RC, TMU, Moradabad.

Email -drskjain2005@rediffmail.com

Date of Submission: 11/10/2013.

Date of Peer Review: 12/10/2013.

Date of Acceptance: 25/10/2013.

Date of Publishing: 29/10/2013 